2019-11-01

Low velocity impact behavior of interlayer hybrid composite laminates with carbon/glass/basalt fibres

Chen, D

http://hdl.handle.net/10026.1/14735

10.1016/j.compositesb.2019.107191

Composites Part B: Engineering

Elsevier

All content in PEARL is protected by copyright law. Author manuscripts are made available in accordance with publisher policies. Please cite only the published version using the details provided on the item record or document. In the absence of an open licence (e.g. Creative Commons), permissions for further reuse of content should be sought from the publisher or author. 


\title{
Low velocity impact behavior of interlayer hybrid composite laminates with carbon/glass/basalt fibres
}

\author{
Dongdong Chen ${ }^{\mathrm{a}}$, Quantian Luo ${ }^{\mathrm{b}}$, Maozhou Meng ${ }^{\mathrm{c}}$, Guangyong Sun ${ }^{\mathrm{a}, \mathrm{d}, *}$ \\ a State Key Laboratory of Advanced Design and Manufacture for Vehicle Body, Hunan \\ University, Changsha, 410082, China \\ b School of Mechanical and Mechatronic Engineering, University of Technology Sydney, \\ NSW, 2007, Australia \\ c School of Engineering, Plymouth University, Plymouth, United Kingdom \\ d School of Aerospace, Mechanical and Mechatronic Engineering, The University of Sydney, \\ Sydney, NSW 2006, Australia \\ * E-mail address: sgy800@126.com
}

\begin{abstract}
This work investigates the effects of carbon/glass/basalt hybridization and fabric structure on the low velocity impact resistance of fibre reinforced plastic composites. Interply hybrid specimens used in the study were fabricated in a sandwich-like stacking sequence using a vacuum assisted resin infusion molding technique. Low velocity impact tests were carried out to study effects of hybridization and fabric structure on the impact resistance of composite laminates. A continuum damage mechanical model was developed and validated for nonhybrid woven fabric laminates at different impact energy levels. Residual damage characteristics in the crosssectional view were identified using a 3D surface scanning system and an X-ray computed tomography (CT) method. On the basis of experimental results, numerical simulation was conducted to analyse the damage mechanisms of the hybrid laminates. Experimental results showed that: (a) hybrid laminates with carbon fibre as the core exhibited superior impact resistance for sandwich-like stacking sequence; (b) similar impact behaviors appeared for carbon laminates hybrid with either basalt or glass fibre; (c) for basalt fibre, weave fabric composite laminates exhibited better energy absorption capability and deformation resistance than cross-ply laminates reinforced by unidirectional fabrics.

Keywords: Hybrid composite, Low-velocity, Finite element analysis, Carbon fibre, Basalt fibre, Glass fibre
\end{abstract}




\section{Introduction}

In present days, fibre reinforced composite materials are widely used as structural elements of aerospace vehicles, automobile and marine due to their excellent specific strength, weight reduction and anti-resistance properties [1]. During its service life, composite structures are exposed to various loading cases which could be categorized as static and dynamic ones. Impact damage on composite structures has been classified into two general categories according to impact damage modes as non-penetrating impacts and complete penetration [2]. Without obvious visual damage on impacted surface compared to that of complete penetration, internal damage caused by lowvelocity impact often induces a significant reduction on the mechanical properties $[3$, 4]. Some fundamental works have been done to understand the exact nature of impact events $[2,5-8]$.

In the previous studies, impact energy was absorbed accompanying with three major failure modes: matrix cracking, delamination and fibre breakage [5, 9]. These failure modes are strongly dependent on several factors including fibre type, resin system, layup, thickness, loading velocity and projectile shape [10]. Sutherland and Guedes Soares [11] made quasi-static impact testing to predict the dynamic impact behaviour of glass fibre-reinforced plastic (GFRP) composites. It was found that fibre failure mechanisms were strain rate dependant, rather than the undamaged and delaminated responses. To simulate the real loading conditions, multiple factors have been considered including temperature [12], repeated impact [13] and coupling cases $[14,15]$. Results from [16] showed that damage became severer with the increase of scale size if impact energies above the damage threshold. Many other publications have considered the reduction of mechanical performance due to the impact damage, such as residual tensile strength [17], residual flexural strength [18] and residual compression strength [19].

Finite element (FE) method offers a fast and repeatable description of complex internal damage mechanisms of composite laminates under impact loadings, which avoided time-consuming high-cost physical tests [20]. A proper constitutive law is 
crucial to describe the actual damage modes in various phases (matrix, fibre and their interfaces) and their interaction relationships. A large number of previous researches mainly felt into two categories as discrete models [8] and continuum damage mechanics (CDM) [21]. When mechanical behaviour of each layer satisfies failure criteria, the computational elements lose their load carrying capability progressively in CDM type which differs to that of discrete type. Initially, damage criteria, such as Hashin [22], Chang-Chang [23] and Hou et al. [24], were developed for unidirectional fibres and used particularly in 2-D problems which only considered the in-plane stress state. In those following researches, various approaches were proposed to capture matrix cracking and delamination as cohesive elements [20] and spring elements [8]. The forms of these damage models were extended to 3-D structure aiming to consider through thickness stresses by $[25,26]$. Constitutive laws for plain wove composites can be used to characterise the general form of damage models from unidirectional composites [16, 26-28].

According to researches above mentioned, a number of work has been carried out to alleviate the intrinsic vulnerable damage of composite laminates under low-velocity impact. One successful example was to improve the impact toughness of thermoset resins, which has been widely used in industry due to relatively low cost and processing considerations [29]. By adding various nanoparticle (multi-wall carbon nanotubes and nanoclay) to the resin, impact resistance of composite was found to be improved compared to that with no particles $[29,30]$.

Another effective way was the hybridization, which could be implemented by replacing brittle fibres (carbon fibres) with ductile fibres (with a larger failure strain) [31]. In this respect, advantages of lightweight properties are maintained while material cost has also been reduced at the same time. Glass fibres seem to be a good candidate from the view of cost, availability and ease of processing [32, 33]. Effects of fabric structure on low-velocity impact response have been conducted in [34, 35], which concluded that 2D woven fabric showed a superior impact performance to unidirectional GFRP composites. Hybrid CFRP composite laminates also showed an improvement of load carrying capability under impact compared to pure carbon fibre 
laminates [5, 33, 36, 37]. González et al. [37] claimed that energy absorption and penetration thresholds were optimized with a hybrid mass ratio of 37:63 for glass/carbon hybrid composites compared with pure composites. Hybrid stacking sequences of carbon/glass fibres played a vital role for material behaviour, particularly the in-plane composite stiffness under low-velocity impact conditions [37]. The authors reported that replacing core laminas with glass fibres achieved elevated damage resistance compared to that of non-hybrid glass laminates under impact test. Similar conclusions also appeared in [33] that placing carbon layers at outer surfaces of laminate has helped to reduce the size and defection of damage area.

Basalt fibre have been widely used in military, such as anti-ballistic applications and automobile and aerospace applications [38]. In recent years it has been considered as an alternative fibre to glass fibres due to its good mechanical properties especially at high temperature, environmental manufacturing process and low cost. Several works on the comparison of mechanical properties between basalt and glass fibres had been conducted $[6,38,39]$ : i.e. tension, compression, flexural, shear and low-velocity impact and post-impact flexural tests. Researches have shown that the hybridization of carbon/basalt fibres has reduced the quasi-static mechanical properties such as strength and modulus compared to non-hybrid carbon fibre-reinforced plastic (CFRP) laminates $[40,41]$, however the low-velocity and high-velocity impact damage resistance of carbon/basalt fibres hybrid laminates were found to be enhanced compared to pure carbon laminates $[32,42]$.

It has appeared that not too many efforts have been paid on the study of low-velocity impact resistance of hybrid composites with carbon/basalt/glass fibres. A relatively low impact energy was considered to study the hybrid effects in [42]. As illustrated in [34, 35], glass fabric structure showed different effects on impact damage behaviour in terms of unidirectional, 2D woven and 3D orthogonal. More works are required to investigate the progressive failure mechanisms if replacing glass fibre with basalt fibre in hybridization laminates. Finite element simulation is an excellent method for further understanding of failure mechanisms and reducing test costs. However, from the 
previous literatures, very rare studies were conducted to simulate the impact behaviour of hybrid laminates due to the complexity of hybrid laminates.

In the present work, inter-layer hybrid laminates were prepared combining carbon, basalt and glass fibres as reinforcements and epoxy resin as matrix. Some typical symmetric sandwich-like layup sequences were considered. A series of low-velocity impact tests were carried out for both hybrid and non-hybrid laminates. The size and shape of residual deformation area at both faces were measured using a 3D laser scanner, and internal damage was inspected by the X-ray Computed Tomography (CT) method after tests. Comparison between experimental and numerical simulations was conducted by a FE model based on CDM law, and then an energy absorption mechanism for hybrid laminates was derived.

\section{Experimental procedure}

\subsection{Materials and specimen preparation}

Plain weave carbon/basalt/E-glass and unidirectional basalt fabrics were used in this study, as shown in Fig.1. Plain-woven carbon (T300, 3K, $\left.198 \mathrm{~g} / \mathrm{m}^{2}\right)$ and E-glass (300 tex, $295 \mathrm{~g} / \mathrm{m}^{2}$ ) fabrics were supplied by Weihai Guangwei Composites Co., Ltd. Basalt fabrics were the product of Sichuan Aerospace Tuoxin Basalt Industrial Co., Ltd. Unidirectional and plain weave basalt fabrics have a density of $300 \mathrm{~g} / \mathrm{m}^{2}$ and $315 \mathrm{~g} / \mathrm{m}^{2}$ respectively. Epolam 5015 (resin) and epolam 5014 (hardener), which were provided by Sino Composite Co., Ltd, were used as the matrix material with a mixture ratio of $3: 1$.

Symmetric sandwich-like stacking sequences were designed to avoid the mismatch of thermal expansion of the hybrid laminates, as presented in Table 1. Hybrid ratio of carbon fibre was maintained as a constant of $50 \%$ for all hybrid laminates. For the convenience in this study, each laminate was designated a code. For example, CBC represents eight basalt layers at the centre as core and four carbon layers at each side as skins. Non-hybrid laminates were also manufactured as a reference. C-20 means the laminate is composed of sixteen carbon layers and impacted with $20 \mathrm{~J}$ energy. Stacking 
sequence of unidirectional basalt layers was [0/90]4S according to ASTM D7136/ D7136M for comparison with weave ones.

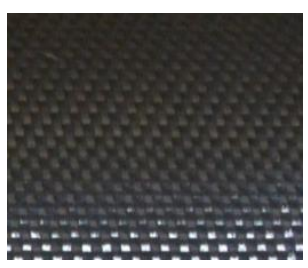

woven carbon

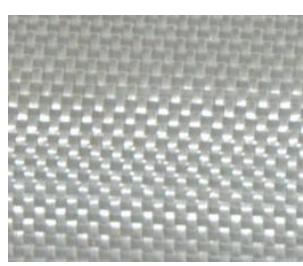

woven E-glass

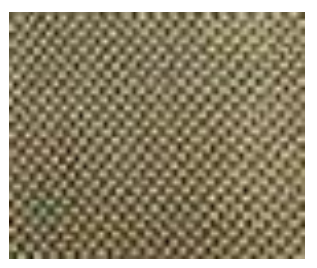

woven basalt

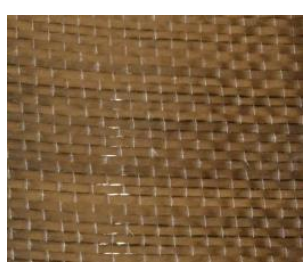

unidirectional basalt

Fig. 1. Illustration of fibre fabrics.

Table 1

Laminate details and impact test configuration.

\begin{tabular}{|c|c|c|c|}
\hline Laminate code & Layup & Number of fabric plies & Impact energy $(\mathrm{J})$ \\
\hline \multicolumn{4}{|c|}{ (A) Plain weave fabriclepoxy for hybrid laminates } \\
\hline $\mathrm{CBC}$ & {$\left[\mathrm{C}_{4} \mathrm{~B}_{4}\right]_{\mathrm{S}}$} & 16 & 50 \\
\hline $\mathrm{BCB}$ & {$\left[\mathrm{B}_{4} \mathrm{C}_{4}\right]_{\mathrm{S}}$} & 16 & 50 \\
\hline CGC & {$\left[\mathrm{C}_{4} \mathrm{G}_{4}\right]_{\mathrm{s}}$} & 16 & 50 \\
\hline GCG & {$\left[\mathrm{G}_{4} \mathrm{C}_{4}\right]_{\mathrm{s}}$} & 16 & 50 \\
\hline BGB & {$\left[\mathrm{B}_{4} \mathrm{G}_{4}\right]_{\mathrm{s}}$} & 16 & 50 \\
\hline GBG & {$\left[\mathrm{G}_{4} \mathrm{~B}_{4}\right]_{\mathrm{s}}$} & 16 & 50 \\
\hline CBGBC & {$\left[\mathrm{C}_{4} \mathrm{~B}_{2} \mathrm{G}_{2}\right]_{\mathrm{s}}$} & 16 & 50 \\
\hline BGCGB & {$\left[\mathrm{B}_{2} \mathrm{G}_{2} \mathrm{C}_{4}\right]_{\mathrm{S}}$} & 16 & 50 \\
\hline \multicolumn{4}{|c|}{ (B) Plain weave fabriclepoxy for non-hybrid laminates } \\
\hline $\mathrm{C}-20$ & {$\left[\mathrm{C}_{16}\right]$} & 16 & 20 \\
\hline $\mathrm{C}-35$ & {$\left[\mathrm{C}_{16}\right]$} & 16 & 35 \\
\hline$C-50$ & {$\left[\mathrm{C}_{16}\right]$} & 16 & 50 \\
\hline B-50 & {$\left[\mathrm{B}_{16}\right]$} & 16 & 50 \\
\hline B-60 & {$\left[\mathrm{B}_{16}\right]$} & 16 & 60 \\
\hline B-70 & {$\left[\mathrm{B}_{16}\right]$} & 16 & 70 \\
\hline G & {$\left[\mathrm{G}_{16}\right]$} & 16 & 50 \\
\hline \multicolumn{4}{|c|}{ (C) Unidirectional fabriclepoxy for non-hybrid laminates } \\
\hline UD-B-50 & {$[0 / 90]_{4 \mathrm{~S}}$} & 16 & 50 \\
\hline UD-B-60 & {$[0 / 90]_{4 \mathrm{~S}}$} & 16 & 60 \\
\hline
\end{tabular}

Vacuum assisted resin infusion molding (VARIM) was adopted here to produce all the composite panels, which was considered as low-cost manufacturing process while obtaining high quality of composites [36, 43]. Epoxy resin was infused at room temperature (about $28^{\circ} \mathrm{C}$ ) and then the composite laminates were cured for 24 hours at the pressure of $-0.1 \mathrm{MPa}$. Rectangular $330 \times 330 \mathrm{~mm}$ plates were got and then cutting into dimensions of $100 \times 100 \mathrm{~mm}$. The thickness of composite plates were measured as 3.6-3.8 $\mathrm{mm}$. 


\subsection{Low-velocity impact tests}

Low-velocity impact test were conducted using INSTRON 9350 drop weight testing machine, of which detailed information had been introduced in the authors' previous work [44]. The crosshead/weight was $7.131 \mathrm{~kg}$ and a hemisphere shaped impactor with a diameter of $12.7 \mathrm{~mm}$ was kept as a constant value for all the tests. Relationships among impact force, displacement, velocity and time data were recorded directly by the testing system. Details of impact configurations have been listed in Table 1. Hybrid laminates were impacted at the same energy of $50 \mathrm{~J}$ while three impact energies were chosen for those non-hybrid laminates in order to investigate the damage state under different impact cases.

\subsection{Post-failure inspection}

To investigate the failure mechanisms of low velocity of impact, surface morphology of both top and bottom surfaces of composite laminates were inspected by using the GOM ATOS 3D surface scanning system (www.gom.com, Braunschweig, Germany). The system used a 3D optical method to capture the details of specimen surface with a resolution of $0.02 \mathrm{~mm}$. X-ray CT as a non-destructive method was used to inspect the fracture surfaces near the impacted laminates, and then the specimens were cut and polished for further inspection by an optical microscope. Then damage and failure modes near the impacted area were compared cross-sectional view.

\section{Numerical modelling}

Composite structures present complicated mechanical response due to their heterogeneous microstructure, vast dissimilarity, sensitivity towards reinforcement directions and presence of interface layer [45]. Two major failure modes were considered here for composite laminates under low-velocity impact: (a) Fibre and matrix failure within intra-ply which was described by CDM approach. A user-defined Vumat subroutine was coded for computation via ABAQUS/Explicit 6.13. (b) Delamination in inter-ply which was modelled by cohesive zone technique. The 
detailed constitutive material models and input material parameters would be introduced in section 3.1 and 3.2.

The loading process in numerical model was the same as the real test condition, in which a square plate clamped by two circular fixtures subjected to low-velocity impact by a rigid impactor as shown in Fig. 2. As reported in [46], every two adjacent plies were considered as a single layer and SC8R element was chosen in order to reduce the computation cost. Then the composite layers were meshed with a size of $1 \times 1 \times 0.5 \mathrm{~mm}$. In addition, cohesive contact was inserted between adjacent mesh layers to simulate the delamination damage. During the impact process, the impactor and both fixtures were modelled as rigid body without deformation. The total number of elements (involving volume elements and interface elements) was approximately 99644.

With the same drop weight testing machine used in [44], the square composite plate was supported by both circular fixtures with an inner diameter of $76 \mathrm{~mm}$ during the simulation process. Displacement in the $Z$-axis direction was only permitted for the impactor to simulate the impact behaviour. A lumped reference mass of $7.131 \mathrm{~kg}$ and initial velocity was defined through a reference point located on the impactor. General contact algorithm in ABAQUS/Explicit was adopted to simulate the possible interactions between impactor, specimen and fixtures. The penalty method with friction coefficient of 0.15 and hard contact were considered in the normal and tangential direction.

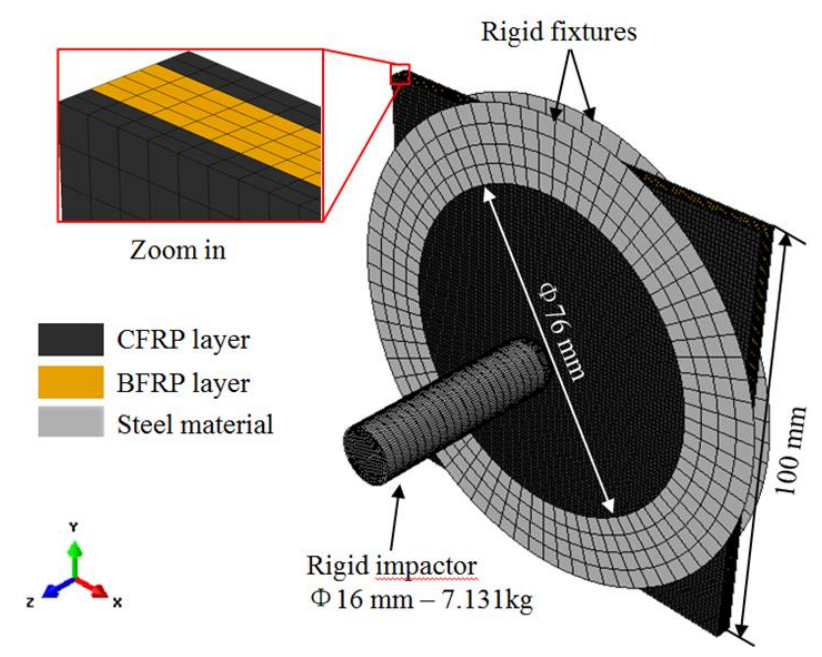

Fig. 2. Finite element model for simulation of impact test. 


\subsection{Constitutive laws for intraply layer}

The composite plates composed of plain weave fabric are often considered as homogeneous and transversely isotropic material due to its similar performance in the warp and weft direction $[16,27,47]$. Three major damage modes were considered here as the previous publication [45]: the fibre fracture damage along warp/weft direction (1/2-direction) and fibre-matrix degradation due to in-plane shear (12-direction). Damage modes were characterized with a set of scalar damage variables $d_{i}(i=1,2,12)$ [27], as shown in Eq. (1),

$$
\left\{\begin{array}{l}
\varepsilon_{11} \\
\varepsilon_{22} \\
\varepsilon_{12}
\end{array}\right\}=\left[\begin{array}{ccc}
\frac{1}{\left(1-d_{1}\right) E_{1}} & -\frac{v_{12}}{E_{1}} & 0 \\
-\frac{v_{21}}{E_{2}} & \frac{1}{\left(1-d_{2}\right) E_{2}} & 0 \\
0 & 0 & \frac{1}{\left(1-d_{12}\right) 2 G_{12}}
\end{array}\right]\left\{\begin{array}{c}
\sigma_{11} \\
\sigma_{22} \\
\sigma_{12}
\end{array}\right\}
$$

where $\varepsilon=\left\{\varepsilon_{11}, \varepsilon_{22}, \varepsilon_{12}\right\}^{T}$ and $\sigma=\left\{\sigma_{11}, \sigma_{22}, \sigma_{12}\right\}^{T}$ are the strain and stress vectors, respectively; $\quad E_{i}$ refers to the Young's moduli along warp and weft direction; $G_{12}$ is in-plane shear modulus. Damage parameters were initially set as 0 and vary between 0 and 1 once damage initiated.

The damage induced by tensile or compressive failures was calculated separately as Eq. (2) [27],

$$
d_{i}=d_{i+} \frac{\left\langle\sigma_{i i}\right\rangle}{\left|\sigma_{i i}\right|}+d_{i-} \frac{\left\langle-\sigma_{i i}\right\rangle}{\left|\sigma_{i i}\right|}
$$

where $d_{i+}$ and $d_{i-}$ represent the tensile and compressive damage variable $(i=1,2)$. Failure surfaces in elastic domain can be described in terms of damage activation functions as [27]:

$$
\begin{aligned}
& F_{i+}=\frac{\sigma_{i+}}{X_{i+}}-r_{i+} \leq 0 \quad F_{i-}=\frac{\sigma_{i-}}{X_{i-}}-r_{i-} \leq 0 \\
& r_{i+}(t)=\max _{\tau \leq t} \frac{\sigma_{i+}}{X_{i+}}(\tau) \quad r_{i-}(t)=\max _{\tau \leq t} \frac{\sigma_{i-}}{X_{i-}}(\tau)
\end{aligned}
$$


where $X_{i+}$ and $X_{i-}$ are the corresponding ultimate tensile and compressive strength along fibre direction, $i=1,2, r_{i+}$ and $r_{i-}$ refer to the damage threshold parameters which were set to 1 and increase with damage progression. The composite loses its strength and decreases gradually after damage activation functions great than 0 . Finally, the evolution of the damage variable followed exponential decay of the form [27] $(\alpha= \pm 1, \pm 2)$ :

$$
d_{\alpha}=1-\frac{1}{r_{\alpha}} \exp \left[-\frac{2 g_{0}^{\alpha} L_{c}}{G_{f}^{\alpha}-g_{0}^{\alpha} L_{c}}\left(r_{\alpha}-1\right)\right]
$$

where $G_{f}^{\alpha}$ is the fracture energy density; $g_{0}^{\alpha}$ is the fracture energy per unit area which could be calculated as $g_{0}^{\alpha}=G_{f}^{\alpha} / L_{c}$. The characteristic length $\left(L_{c}\right)$ of the element could be evaluate by the ABAQUS/Explicit software.

The in-plane shear stress can cause matrix failure and thus result a non-linear plastic behaviour as described in $[27,48]$. While as analysed in $[16,45]$, the mechanical behaviour of matrix was overwhelmed by the fibre fracture and delamination in impact loading cases. Thus the maximum shear stress criteria should be considered and the associated element was degraded directly after stress exceeds the ultimate strength. The material parameters used in this are given in Table 2.

\section{Table 2}

Material parameters of the CFRP and BFRP laminates.

\begin{tabular}{|c|c|c|}
\hline Description & CFRP & BFRP \\
\hline Young's moduli (GPa), $E_{1}=E_{2}$ & 50.38 & 19.09 \\
\hline Poisson's ratio, $v_{12}$ & 0.052 & 0.090 \\
\hline Shear moduli $(\mathrm{GPa})^{\mathrm{a}}, G_{12}$ & 3.0 & 1.54 \\
\hline Ultimate tensile strength (MPa), $X_{1+}=X_{2+}$ & 504 & 413 \\
\hline Ultimate compressive strength (MPa), $X_{1-}=X_{2-}$ & 320 & 200 \\
\hline In-plane shear strength $(\mathrm{MPa})^{\mathrm{a}}, G_{12}$ & 109 & 80 \\
\hline Fracture energy $(\mathrm{N} / \mathrm{mm})^{\mathrm{a}}, G_{f}^{1+}=G_{f}^{1-}=G_{f}^{2+}=G_{f}^{2-}$ & 40 & 130 \\
\hline
\end{tabular}

Note: Properties were mainly obtained from Ref. [43].

a Predicted value in this study.

\subsection{Constitutive laws for interface layer}


Interface damage, representing the delamination between adjacent plies, appears to be a major damage mode in the low-velocity impact event [48]. A generalized bi-linear traction-separation law was used in the present work to simulate delamination damage behaviour as done in [27]. Interface damage initiated once function of the quadratic stress failure criteria reached 1.0 [49]:

$$
\left\{\frac{\left\langle t_{n}\right\rangle}{t_{n}^{o}}\right\}^{2}+\left\{\frac{t_{s}}{t_{s}^{o}}\right\}^{2}+\left\{\frac{t_{t}}{t_{t}^{o}}\right\}^{2}=1
$$

where $t=\left\{t_{n}, t_{s}, t_{t}\right\}^{T}$ is the nominal traction vector and $t_{o}=\left\{t_{n}^{o}, t_{s}^{o}, t_{t}^{o}\right\}^{T}$ represents the peak value of the contact stress. Evolution of interface damage was controlled with Benzeggagh-Kenane (BK) law [27], with the traction stress reducing gradually to zero:

$$
G_{n}^{C}+\left(G_{s}^{C}-G_{n}^{C}\right)\left\{\frac{G_{s}}{G_{t}}\right\}^{\eta}=G^{C}
$$

where $G_{n}^{C}$ and $G_{s}^{C}$ refer to the critical fracture energies in normal and shear direction, respectively. $G_{n}$ and $G_{s}$ are the amount of energy done by $t_{n}$ and $t_{s} \cdot \eta$ denotes the material coefficient and is conventionally defined as 2.284 here. The relevant material data for interface are summarized in Table 3.

Table 3

Interface parameters for the CFRP and BFRP [43].

\begin{tabular}{ll}
\hline Description & Value \\
\hline Maximum nominal stress in three directions, $(\mathrm{MPa})$ & $t_{n}^{o}=12, t_{s}^{o}=t_{t}^{o}=26$ \\
Fracture energy $(\mathrm{N} / \mathrm{mm})$ & $G_{n}^{C}=0.504, G_{s}^{C}=1.566$ \\
\hline
\end{tabular}

\section{Experimental results and discussion}

\subsection{Impact responses}

Relationships between contact force and impactor displacement for all tested samples are shown in Fig. 3. Common features could be observed that the contact force increased with small zigzag fluctuations up to the peak force, indicating a progressive failure, and then the force dropped dramatically. The first drop of contact force (at 
incipient point about $1 \mathrm{kN}$ ) was caused by either the matrix cracking or delamination for all laminates, as discussed by previous studies [6]. After reaching the peak point, the force decreased linearly for laminates hybrid with ductility fibres (glass/basalt) which indicated the major damage initialization [6], regardless of laminate configuration and impact energy (shown in Fig. 3). The CFRP laminate performs relatively stable progressive failure process with smaller fluctuations around peak load compared to glass/basalt ones (Fig. 3 (a)). Indeed two different modes appeared in terms of impactor displacement after the peak load (unloading process), corresponding to the impactor returned toward the axis origin (non-penetrated) and kept increasing (penetrated).

As can be observed from Fig. 3 (a), the CFRP laminate exhibits a higher slope of force-displacement curve before peak point and lower penetration resistance compared to basalt/glass ones since it has been penetrated under the same impact energy of $50 \mathrm{~J}$. On the other hand, the GFRP or BFRP laminates presented similar behaviour in terms of curve pattern, indicating similar impact failure process. The reason for a higher peak force performed in BFRP/GFRP laminates could be owned to the global deformation mode caused by fibre ductility discussed in previous study [42]. Specimens hybridized with GFRP or BFRP showed a similar curve pattern in Fig. 3(a)-(c), indicating that ductile fibre dominated the major mechanical performance regardless of stacking sequences under the hybrid ratio of 50\%. For the hybrid laminates, the layup configuration particularly affected the peak load and failure mode (penetration or rebound in the unloading process). The load bearing capability of carbon/glass and carbon/basalt hybrid laminates exhibited little difference in terms of peak load due to the similar mechanical properties of glass and basalt fibres, however the hybrid laminates showed an increase trend compared to pure CFRP laminate. At the meantime pure glass or basalt laminates showed higher load bearing capacity as shown in Fig. 3 (a). It can be noticed in Fig. 3(c) that hybridization with three types of fibres mainly affected the mechanical performance after peak force.

As represented in Fig. 3 (d), the increase of impact energy for woven fabric BFRP laminates caused negligible effect on peak force but larger rebound displacement. It 
appeared that these laminates with weave fabrics were only able to withstand a specific dynamic peak load beyond impact energy of $50 \mathrm{~J}$. For laminates composed of unidirectional fabrics, a higher peak force appeared and the failure mode varied from rebound to penetration with the increase of impact energy (Fig. 3 (d)). Woven fabric laminates performed a considerably larger peak force and slope of force-displacement curves comparing to unidirectional laminates. This is similar to the observation from E-glass in [35].
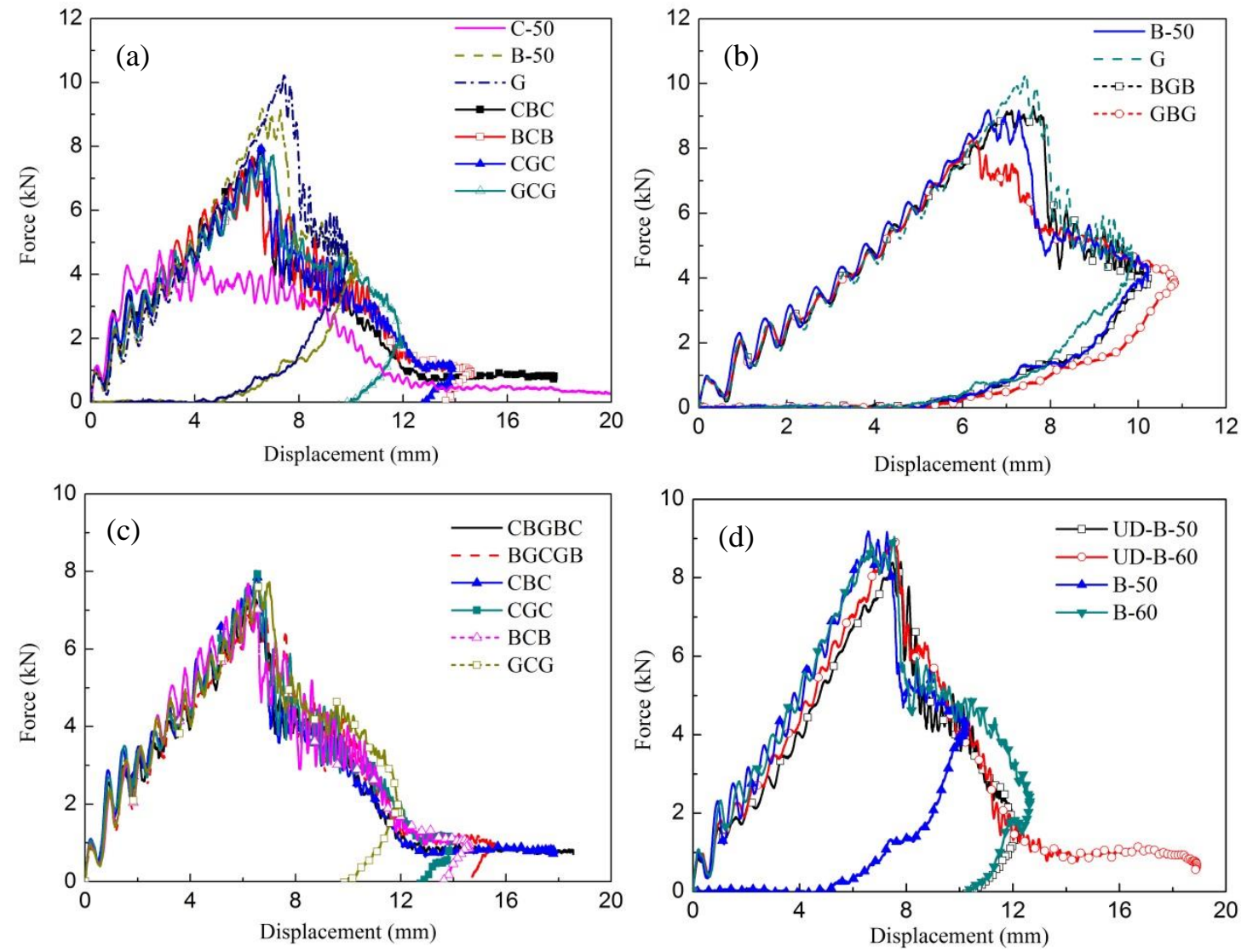

Fig. 3. Impact force vs. displacement curves for hybrid and non-hybrid laminates.

\subsection{Impact resistance comparison}

Laminate configuration strongly affects the failure mechanism and energy absorption as validated in previous studies $[42,50]$. Several parameters, in order to assess the damage accumulation and impact resistance for all laminates, were defined and analysed in this section. Two typical parameters, namely peak force $\left(P_{\max }\right)$, and 
maximum displacement $\left(U_{\max }\right)$ of impactor as most used in $[6,36]$, were chosen to describe the deformation behaviour under impact process. Also, two key impact parameters referred to [50] like energy absorption $\left(E_{a}\right)$ and damage degree ( $D I=E_{p} / E_{i}$, a dimensionless parameter which reveals the utilization of total impact energy toward initiation and propagation energy) were adopted to assess damage process. $E_{i}$ is defined as the energy absorption at $P_{\max }$ point and $E_{p}$ is equal to $E_{a}-E_{i}$ here. All these parameters obtained from force-displacement curves of each hybrid and non-hybrid laminates are summarized in Table 4 and plotted in Fig. 4 - Fig. 5.

The comparison of peak force for all laminates consisted of weave fabrics under impact energy of $50 \mathrm{~J}$ is shown in Fig. 4(a). CFRP laminate showed the minimum peak force while BFRP and GFRP presented a much larger one. Stacking sequence showed limited effect on peak force for sandwich-like configuration: only about $1.8 \%$ and $2.8 \%$ increase when carbon layers was as skins compared to those as the core of carbon/basalt (BCB) and carbon/glass (GCG) hybrid laminates separately. Also, a larger peak force appeared when basalt fibres were used as skins for basalt/glass hybrid laminate. Though performing larger peak force after hybridization with carbon fibre, hybrid with basalt and glass contributed negligible improvement compared to non-hybrid GFRP/BFRP laminates. As for carbon/glass/basalt hybrid laminates, e.g. CBGBC or BGCGB, the peak force appeared relatively smaller than those two-component hybrid laminates, e.g. $\mathrm{CBC}$, CGC, etc/. This is due to the bottom surface-splitting as described in [7] for aramid/basalt hybrid laminates, which caused the reduction of resistance.

Fig. 4(b) exhibits the maximum displacement for laminates impacted with impact energy of $50 \mathrm{~J}$. It can be observed that CFRP laminates showed larger displacement than that of basalt or glass ones. Hybrid laminates performed an intermediate maximum displacement value than that of non-hybrid ones except for penetration cases (CFRP). While a smaller maximum impactor displacement exhibited when carbon layers were 
used as the core in sandwich-like laminate configurations. Hybridization of three types of fibres showed rare variation on this phenomenon.

In terms of energy absorption, GFRP or BFRP laminates absorbed more impact energy when hybridized with carbon fibre, compared to non-hybrid ones (i.e. B-50/G), as shown in Fig.5(a). While stacking carbon layers as core caused better energy absorption than other layup configuration with the same usage of fabrics. However, no obvious change of energy absorption can be found from glass/basalt hybrid laminates with different configurations. According to Fig. 5(b), most of the impact energy was absorbed during the damage propagation process for CFRP laminate while BFRP and GFRP laminate showed opposite trend. Compared to non-hybrid ones (i.e. C-50), $D_{i}$ decreased after the incorporation of basalt or glass layers, indicating the increase of damage initiation energy. Further observation can be seen from Fig. 5(b) that smaller $D_{i}$ can be obtained from sandwich-like stacking sequence when face sheets were replaced with CFRP layers. For hybridization with three types of fibres, similar phenomenon could also be found.

According to Table 4, woven fabrics presented better performance in terms of peak force and maximum impactor displacement compared to unidirectional layers under impact energies of $50 \mathrm{~J}$ and $60 \mathrm{~J}$. However limited difference of energy absorption capability appeared for woven fabric reinforced laminates. Under the impact energy of $50 \mathrm{~J}, \mathrm{~B}-50$ showed a larger $D_{i}$ value than that of UD-B-50, indicating a better resistance to initiation and propagation of delamination failure. The previous publication [36] reported a similar finding. 

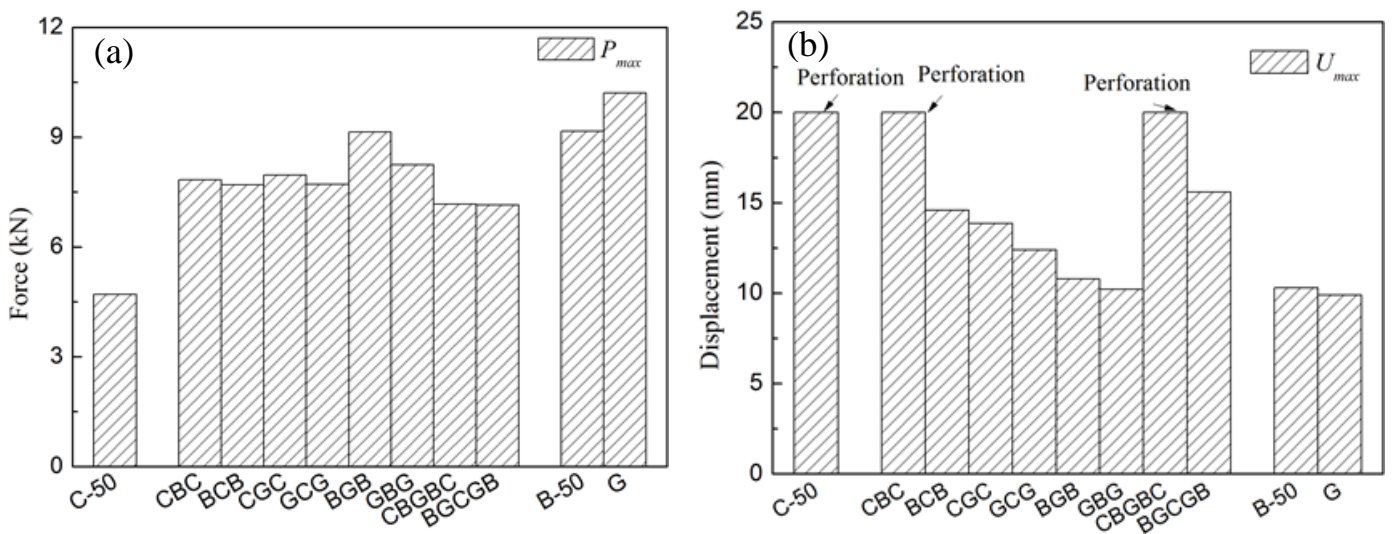

Fig. 4. (a) Peak force and (b) maximum displacement for $50 \mathrm{~J}$-impacted laminates.
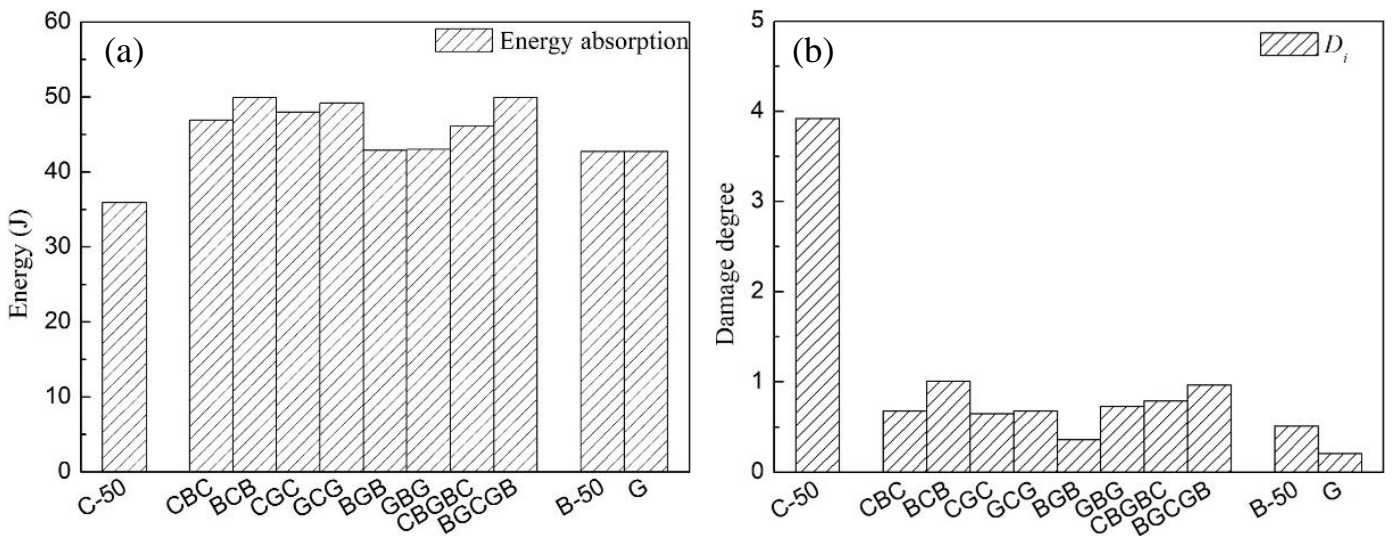

Fig. 5. (a) Energy absorption and (b) damage degree for $50 \mathrm{~J}$-impacted laminates.

\section{Table 4}

Summary of impact characteristic parameters obtained from impact curves.

\begin{tabular}{lllll}
\hline Laminate code & $P_{\max }(\mathrm{kN})$ & $U_{\max }(\mathrm{mm})$ & $E_{a}(\mathrm{~J})$ & $D_{i}$ \\
\hline B-50 & 9.17 & 10.29 & 42.71 & 0.51 \\
B-60 & 8.97 & 12.60 & 59.43 & 0.61 \\
\hline UD-B-50 & 8.35 & 16.65 & 42.70 & 0.45 \\
UD-B-60 & 8.92 & $/$ & 55.00 & 0.63 \\
\hline
\end{tabular}

\subsection{Deformation characteristics at both sides}

To evaluate the impact damage of various configurations, deformation characteristics on both bottom and top surfaces were inspected by visual method. The results are shown in Fig. 6. CFRP laminate was penetrated under impact energy of 50 J which can be clearly seen from impact force-displacement curve plotted in Fig. 3(a). A relatively small circular shape of damage area was observed on the top surface. The bottom surface was completely split along fibre direction, showing multiple crossshaped cracks, which have a larger size than the diameter of impactor. For BFRP and 
GFRP laminates, extended delamination area together with cross-shaped cracks appeared on the top surface, showing rather different damage mechanism. Impact damage accumulated during impact process accompanying with matrix crack, delamination and fibre fracture until the plug formation on the bottom surface. For laminates stacked with unidirectional fabrics, fibre breakage and splitting dominated the failure mode with the increase of impact energy from $50 \mathrm{~J}$ to $60 \mathrm{~J}$, showing rather different failure modes to woven ones. Therefore, woven fabrics showed a balanced mechanical performance which could suppress the damage procession than that of unidirectional fabrics.

Failure modes for hybrid laminates depend on fibre type at both face sheets. Sizes of cross-shaped cracks were reduced after replacing core CFRP laminas by BFRP or GFRP ones in sandwich-like configuration compared to pure CFRP laminate, leading to better impact resistance. Replacing carbon layers at both face sheets enlarged the damage state on bottom surface compared to non-hybrid GFRP or BFRP laminates, in which a larger quantity of fibre breakage can be observed. Hybrid configuration with glass layers as skins and carbon/basalt layers as core showed a great advantage in terms of delamination damage. 


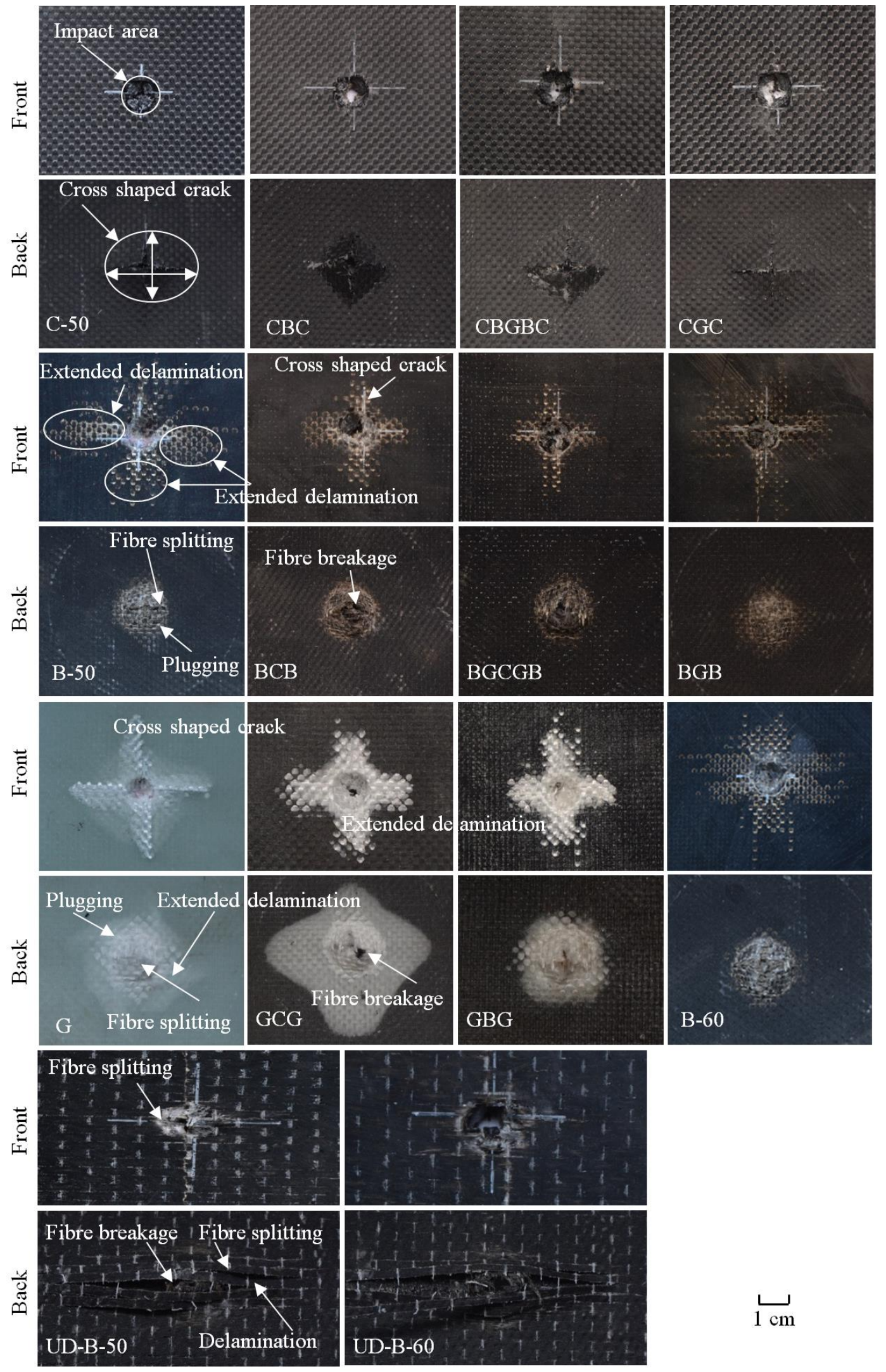

Fig. 6. Front and back photographs of specimens after tests. 
Fig. 7-8 illustrate deformation distribution of specimens after impact tests by using C-scan method. Results of glass fibre hybrid laminates are not shown in the figures because they showed similar deformation mode to that of basalt ones. Damage distribution of all laminates at top surface exhibits similar circular shape which is smaller than diameter of the impactor. With the increase of impact energy, damage area on top surface shows progressive increased trend for BFRP laminates regardless of unidirectional or woven fabrics. The dome-shape deformation area on bottom surface shows larger sizes than that on the top side. Laminates stacked with unidirectional fabrics exhibit a majority of deformation along fibre direction, indicating a different energy absorption procedure under impact.

To better evaluate the damage caused by the impact event, deformation area on top surface and maximum residual deflection of bottom surface has been summarized in Fig. 9-10. It can be observed from Fig. 9 that CFRP laminate shows minimum damage area while a maximum residual deflection value compared to those non-hybrid GFRP/BFRP ones. When carbon layers were hybridized with more compliant ones like basalt/glass fibres, an elevated impact resistance appeared comparing to the pure CFRP laminate which showed a smaller residual deflection but a larger the damage area on top surface. However, the stacking sequence for those carbon hybrid laminates showed negligible effect on damage area under impact energy of $50 \mathrm{~J}$.

The difference of impactor displacement between unidirectional and woven fabrics laminate has been summarized in Fig. 10. Increasing impact energy showed negligible improvement on size of damage area but the deformation mode in terms of residual deflection. Laminates reinforced by unidirectional fabrics intended to yield larger residual deflection together with larger area on bottom surface as observed from Fig. 8 and Fig. 10. This is due to the different failure mechanisms of fibre breakage, delamination and bulge [35]. 


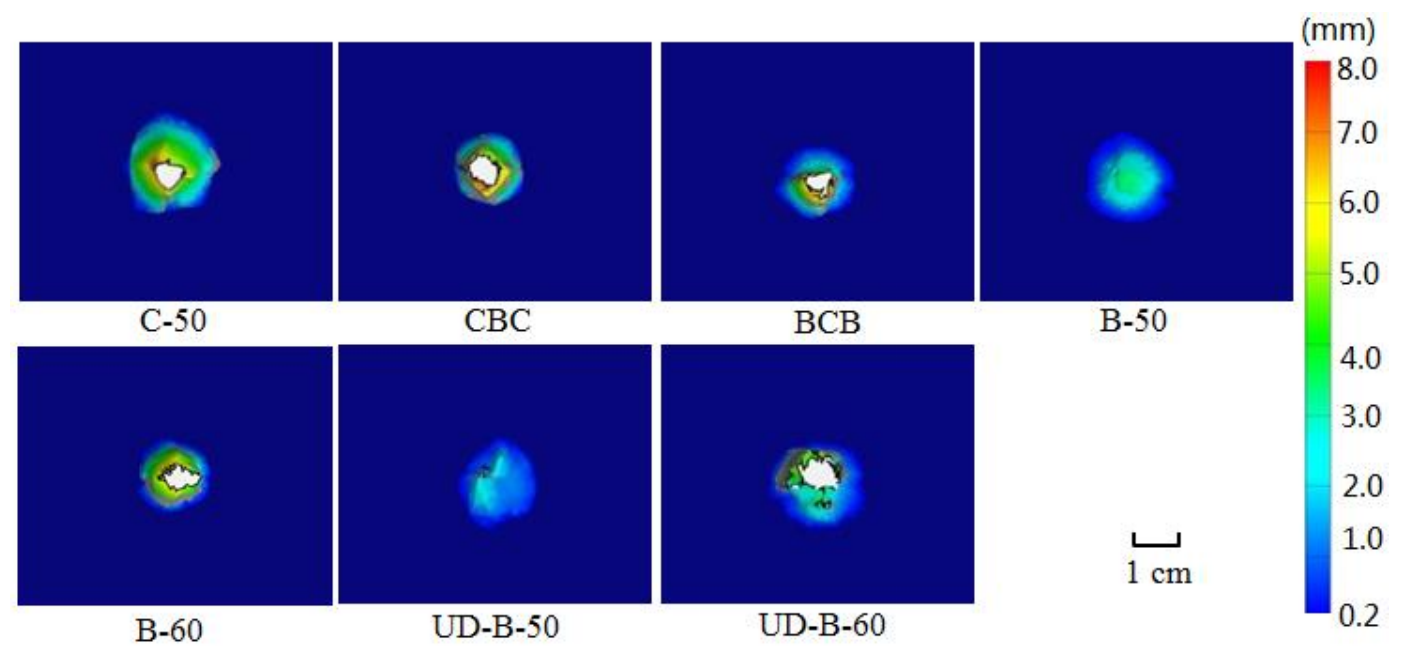

Fig. 7. C-scan inspections of six types of laminates at top surface.

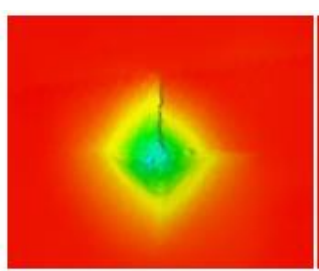

C-50

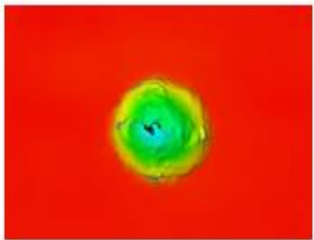

B- 60

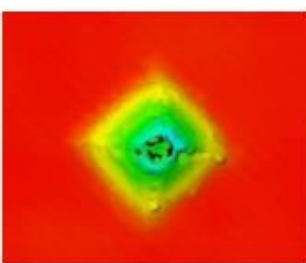

$\mathrm{CBC}$

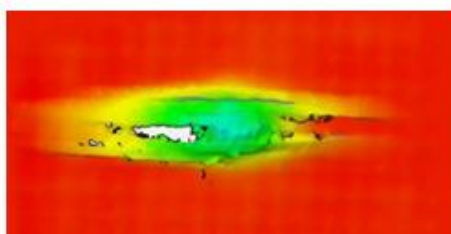

UD-B-50

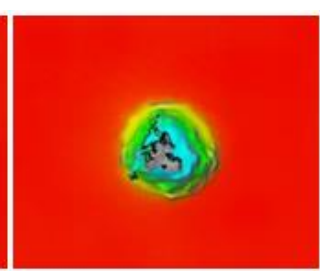

$\mathrm{BCB}$

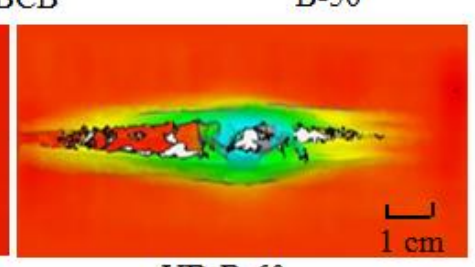

UD-B-60

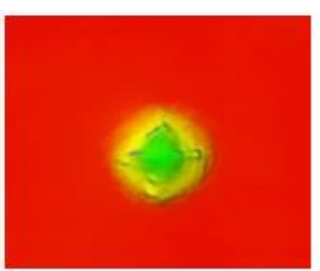

B-50 $(\mathrm{mm})$

0.0

$-1.5$

$-3.0$

$-4.5$

$-6.0$

$-7.5$

$-9.0$

$-10.0$

Fig. 8. C-scan inspections of six types of laminates at bottom surface.
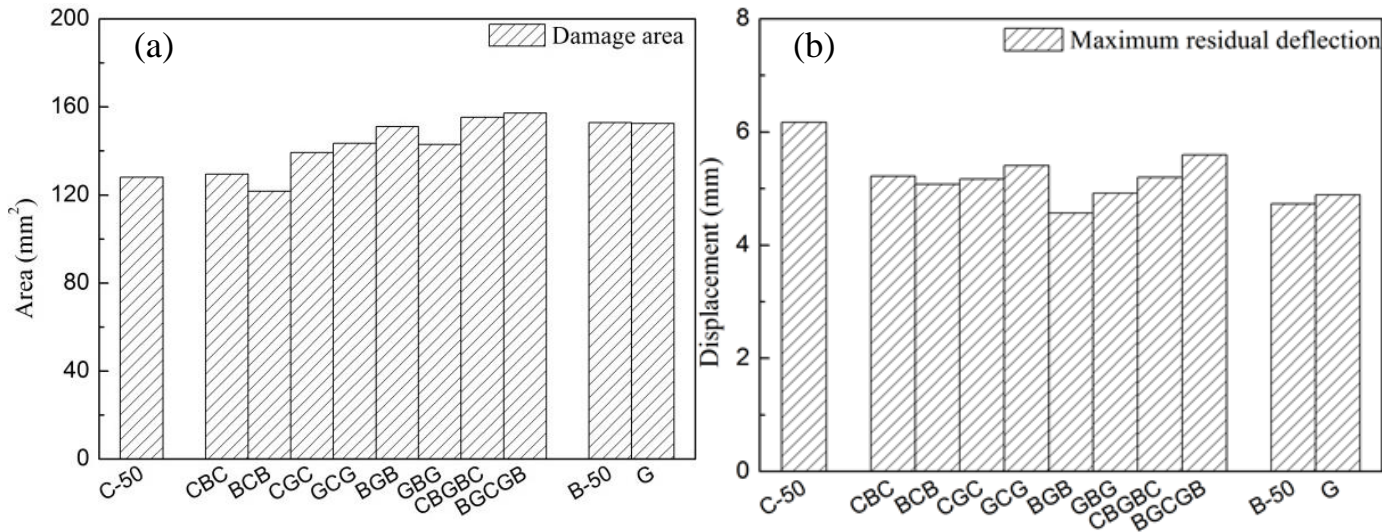

Fig. 9. Deformation data under 50 J-impacted laminates: (a) damage area on top surface and (b) maximum residual deflection depth on bottom surface. 


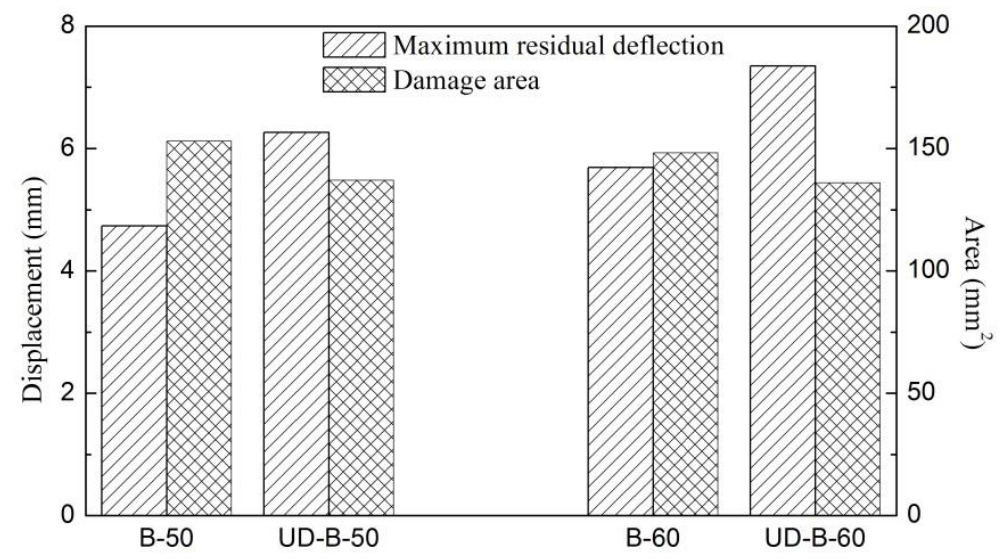

Fig. 10. Comparisons of deformation data between composite laminates reinforced by unidirectional and woven structures.

\subsection{Post-failure damage analysis}

To better classify the difference in impact failure mode between CT (nondestructive) and mechanical cutting (destructive) method, half-sectional view of the damaged region was inspected, as shown in Fig. 11-13, so that the failure mode near the impact area could be validated from the comparison of these figures.

The deformation mode near the impact area consisted of fibre breakage, matrix cracking, fibre bending and delamination within carbon layers, which caused larger delamination region along bottom surface due to the interaction of tensile stress. For basalt layers, fibre breakage and matrix cracking dominated the major failure mode, with less content of delamination. Mixed failure mode appeared within CFRP/GFRP or CFRP/BFRP hybrid laminates. A smaller size of indentation and delamination area can be observed when carbon layers were stacked as core layers, and delamination was more likely to occur at the interface between carbon and basalt layers.

Sizes of impact area and delamination showed an elevated trend when impact energy increased from $50 \mathrm{~J}$ to $60 \mathrm{~J}$ as observed from Fig. 13. Compared with unidirectional laminate, weave ones cause more localized deformation mode and less content of delamination. This is due to the interlock of fibre tows in both two directions. Thus delamination initiation and propagation were suppressed through the thickness direction of laminate during the impact process. 

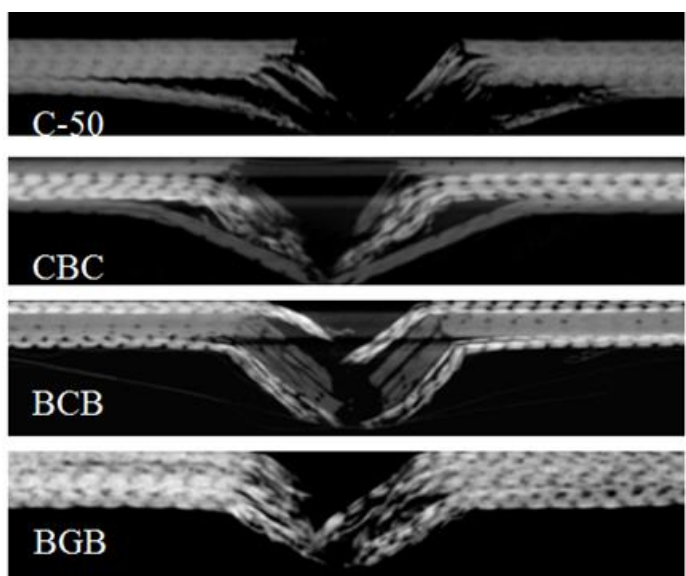
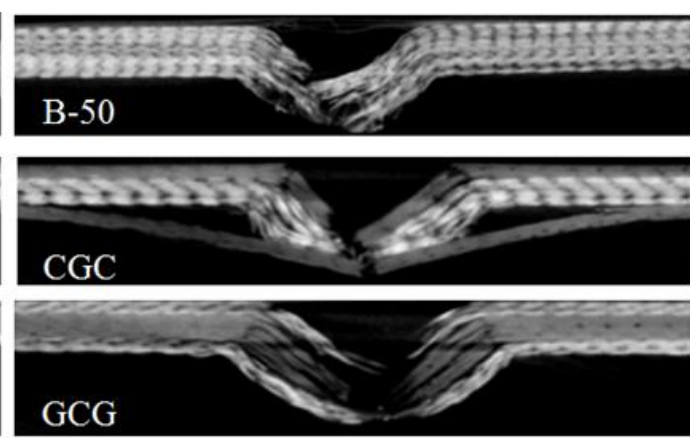

$0.5 \mathrm{~cm}$

Fig. 11. Cross-sectional view of the samples after tests using non-destructive method.
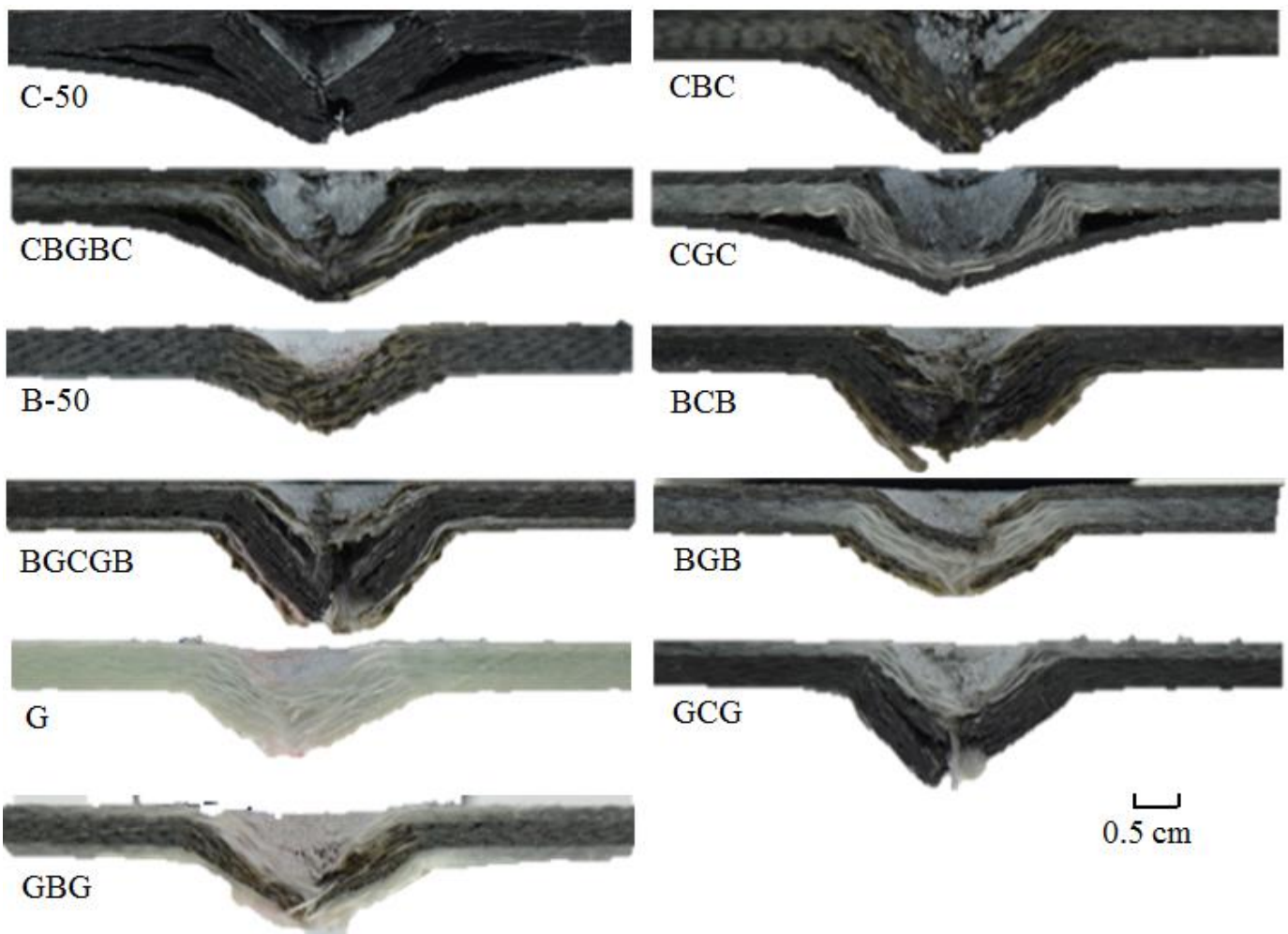

$0.5 \mathrm{~cm}$

Fig. 12. Cross-sectional view of the samples after tests using destructive method.
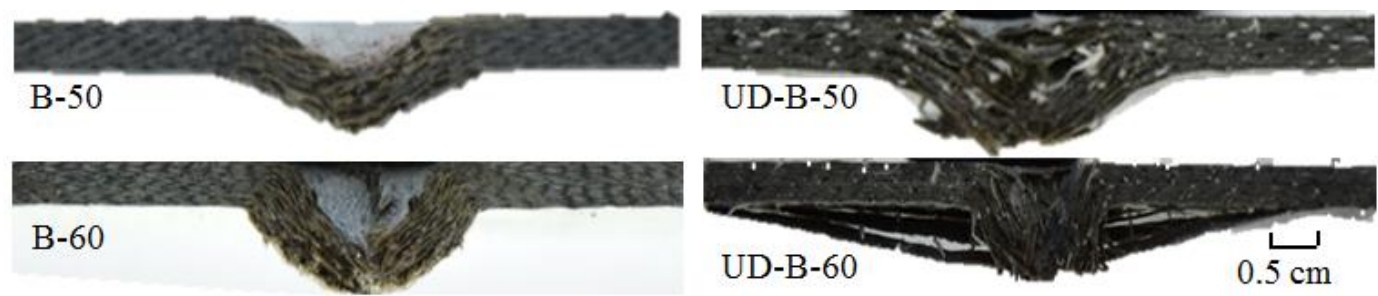

Fig. 13. Cross-sectional view of basalt laminates impacted with impact energy of $50 \mathrm{~J}$ and $60 \mathrm{~J}$.

\section{Numerical analysis compared with experimental results}


Based on the FE model established in section 3, numerical simulation was carried for both non-hybrid laminates (CFRP and BFRP laminates impacted with two different energies, C-20, C-50, B-50 and B-70) and hybrid laminates (CBC and BCB). Detailed information of structural response, including force-displacement curves, shape and size of failure area, and different failure mechanisms for hybrid laminates, will be presented and validated with experimental results in this section.

\subsection{Validation of finite element model}

Fig.14 shows the comparison of impactor force-displacement curves between experimental and numerical results for carbon, basalt and their hybrid laminates under various impact energies. The FE simulation exhibited very similar load-displacement curves for all laminates during the increasing stage of impact force. For basalt and hybrid laminates, the impact forces decreased rapidly after exceeding the peak, leading to weaker mechanical performance. This might be owned to the computation mechanism of CDM model for failed elements. Deletion of failed elements near impact area can provide a better approximation to experimental ones but caused decrease reduction of structural performance. In order to investigate the impact failure mechanism, a detailed inspection of laminate deforming procedure should be carried out by means of two typical time as $T_{1}$ and $T_{2}$, which will be discussed in section 5.2.

Fig. 15 compares the experimental measurement and numerical prediction of residual deformations over both the top and bottom surfaces of hybrid and non-hybrid laminates under impact energy of $50 \mathrm{~J}$. Note that the same contour colour levels were used for both C-scan and FE simulation results. It can be seen that the local indentation on the top surface and failure profile on the bottom surface were predicted reasonably well in terms of damage shape size. Furthermore, comparison of cross-sectional views between CT image and FE results has been summarized and illustrated in Fig. 16 for hybrid and non-hybrid laminates under impact energy of $50 \mathrm{~J}$. Debonding between carbon and basalt layers appeared as a key failure mechanism during the impact process from the illustrated images. The comparison indicates that FE model established here 
was capable of predicting the impact failure process for non-hybrid laminates or carbon/basalt hybrid laminates.
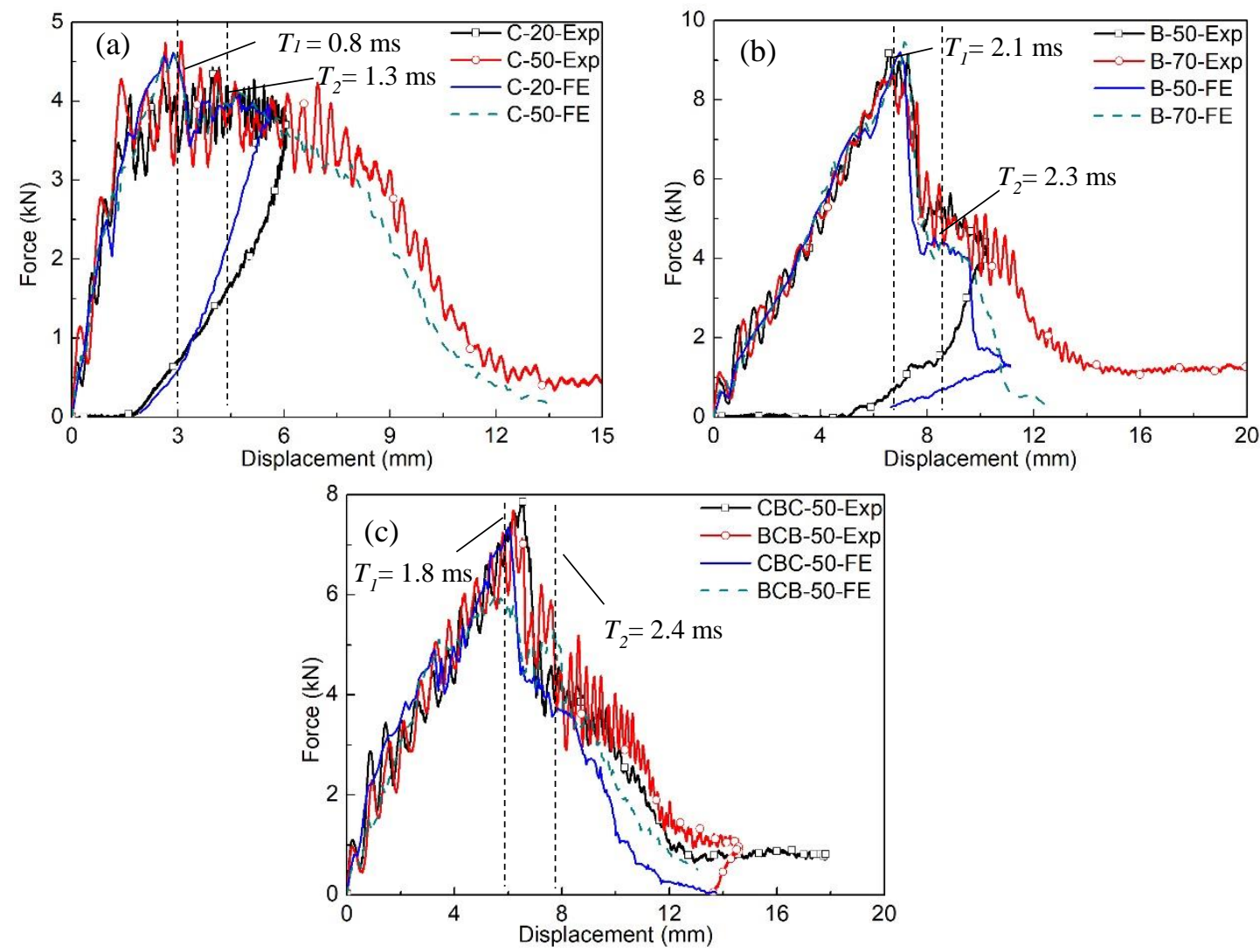

Fig. 14. Comparison between FE prediction and experimental measurement of force-displacement curves for: (a) CFRP laminate impacted with energies of $20 \mathrm{~J}$ and $50 \mathrm{~J}$, (b) BFRP laminate impacted with energies of $50 \mathrm{~J}$ and $70 \mathrm{~J}$ and (c) CFRP/BFRP hybrid laminates with impact energy of $50 \mathrm{~J}$. 

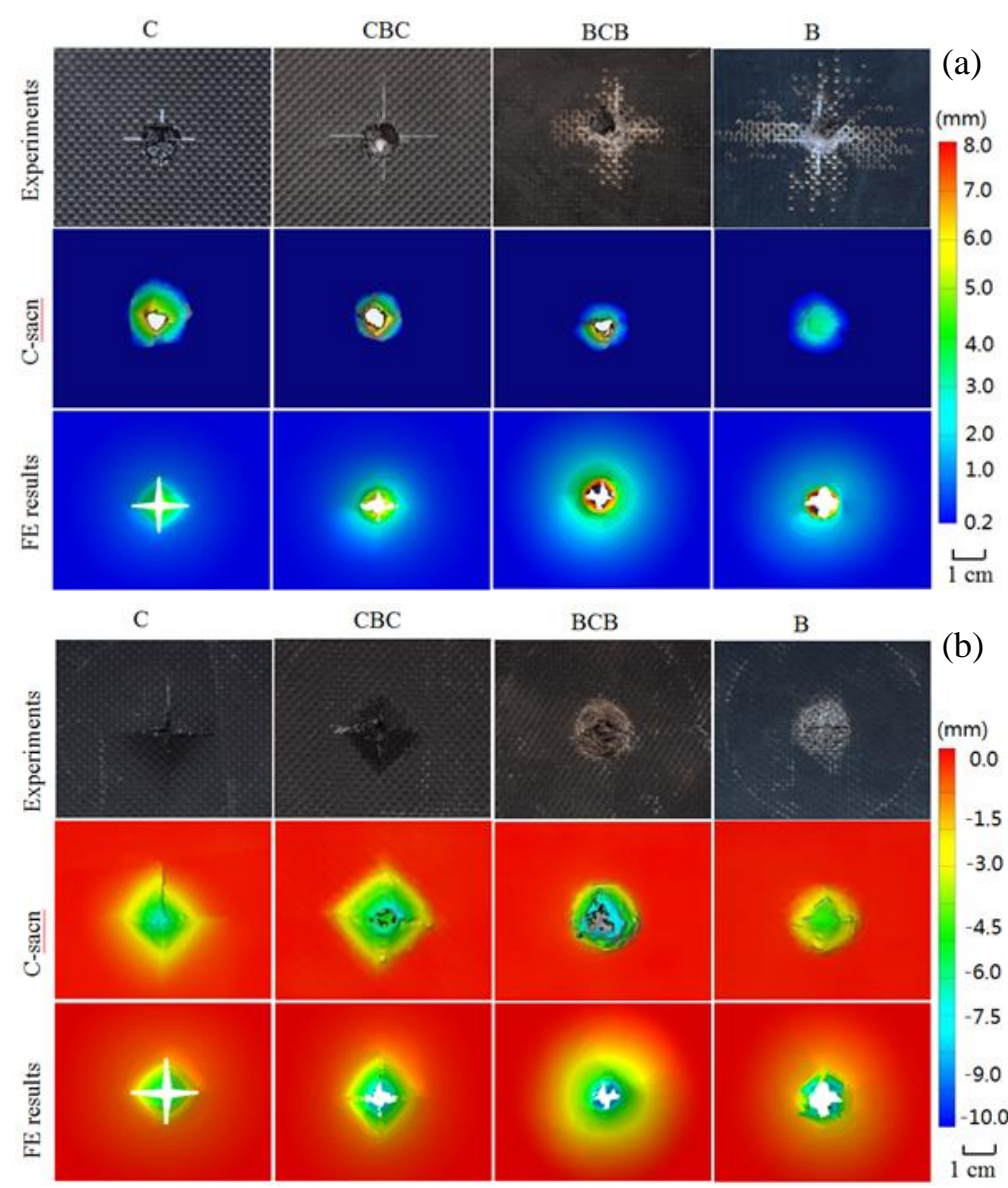

Fig. 15. Comparison of deformation characteristics under impact energy of $50 \mathrm{~J}$ between photographic images from experiments, C-scan and FE simulation for (a) top surface and (b) bottom surface.

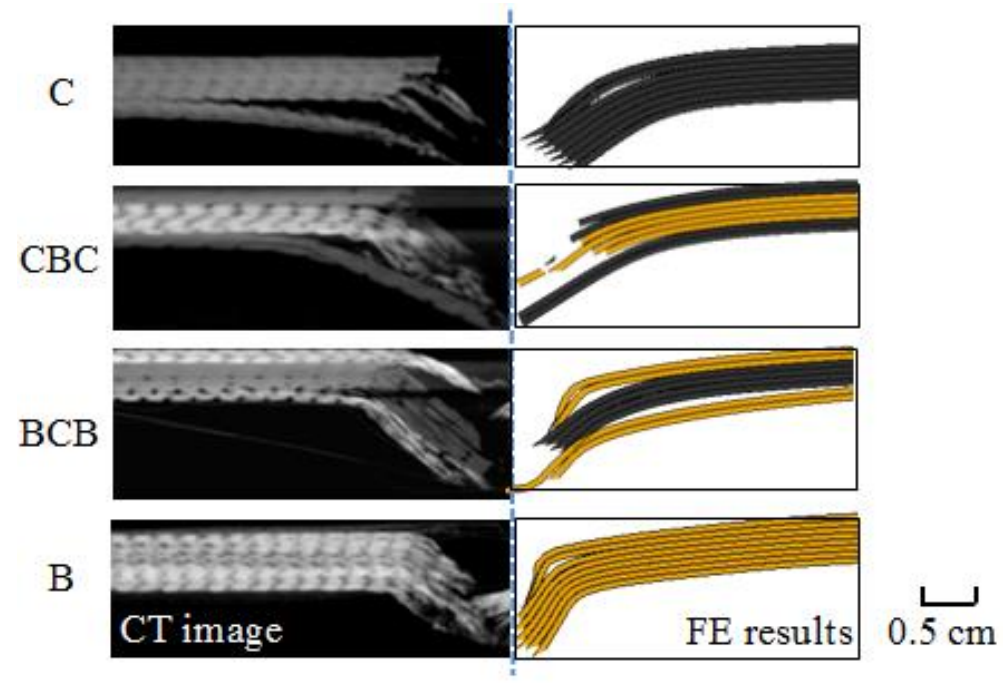

Fig. 16. Comparison between the cross-sectional views from CT scan and FE simulation under impact energy of $50 \mathrm{~J}$. 


\subsection{Energy absorption mechanism}

A schematic of cross-sectional damage for CFRP and BFRP laminates under $50 \mathrm{~J}$ impact energy at typical time points ( $T_{1}$ and $T_{2}$ as shown in Fig. 14) is depicted in Fig. 17. As revealed in previous studies [45], the impact force would firstly increase to the maximum level gradually, during the impact process. Tensile failure in the fibre direction would cause the major load drop after $T_{1}$ time, as descripted by tensile failure factor shown in Fig. 17. It can be observed that tensile failure was severer in the bottom layer due to the larger tensile stress under impact load, as similar to [51]. As a contrast, a larger failure area appeared within BFRP laminate due to its better ductile performance.

A typical failure profile for hybrid laminates from FE model, e.g. $\mathrm{CBC}$ and $\mathrm{BCB}$ is illustrated in Fig. 18. Both hybrid laminates showed similar failure mode: CFRP layers had cracked before the maximum impact force at $T_{1}$ time. In the experimental session, it has been discussed that BFRP layers were in load bearing stage while CFRP layers had been penetrated by the impactor, indicating a higher impact resistance of BFRP layers. It can also be seen that the typical failure of CFRP layers placed at both face sheets completely broke within CBC laminate. Whereas, delamination and CFRP layer crack dominated the main failure mode for BCB laminate, no obvious crack appeared in case of BFRP layers stacking at both face sheets. Then after the major load dropped, BFRP layers failed suddenly within CBC laminate. In another word, BFRP layers in BCB laminate failed following a step-based procedure.

In Fig. 19, the internal energy history profiles of two hybrid laminates (e.g. CBC and $\mathrm{BCB}$ laminate) are represented for a better understanding of the impact damage process. Internal energy acquired for each two plies through ABAQUS/Explicit output variable identifier ALLIE [45]. The evolution process of carbon and basalt layers was plotted with solid and dotted lines separately. Common features could be observed that basalt fibre layers absorbed a relatively larger amount of energy than carbon layers. Thus impact response of hybrid laminates was dominated by basalt layers. After $T_{1}$ time, 
internal energy absorbed within carbon layers remained on a plateau due to the progressive fibre breakage as validated in Fig. 18.

It can be also observed from Fig. 19 that a higher energy absorption by basalt layers could be achieved when carbon layers were stacked as the core (BCB) before $T_{2}$ time. The distribution of energy absorption tended to be in balance among the layers with the same fibre, leading to a better energy absorption performance for the whole structure and as a result the $\mathrm{BCB}$ laminate exhibited a higher damage resistance than that of $\mathrm{CBC}$ laminate in Fig. 5.

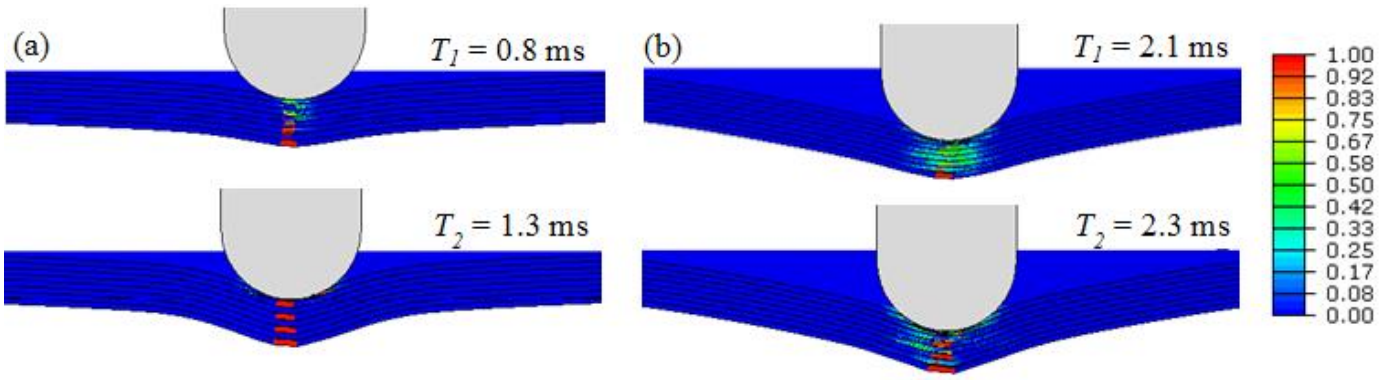

Fig. 17. FE prediction of the tensile failure deformation profiles for non-hybrid laminates under 50 J impact energy at some typical time: (a) CFRP laminate and (b) BFRP laminate.
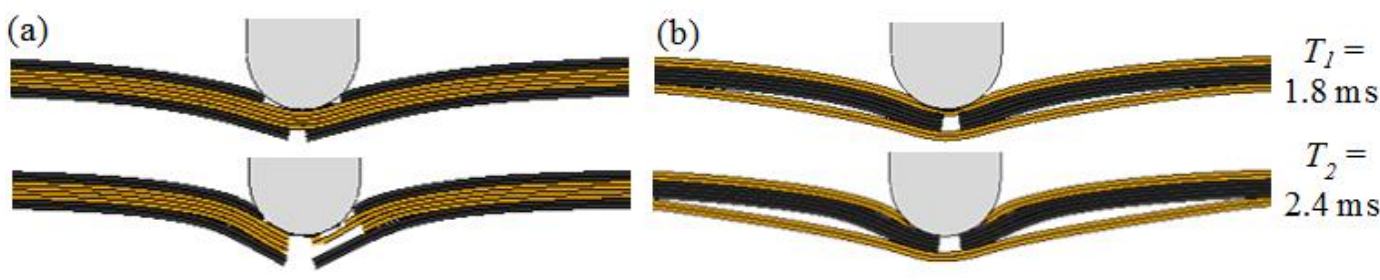

Fig. 18. Numerically predicted sectional views of hybrid laminates impacted under energy of $50 \mathrm{~J}$ for (a) CBC laminate and (b) BCB laminate.
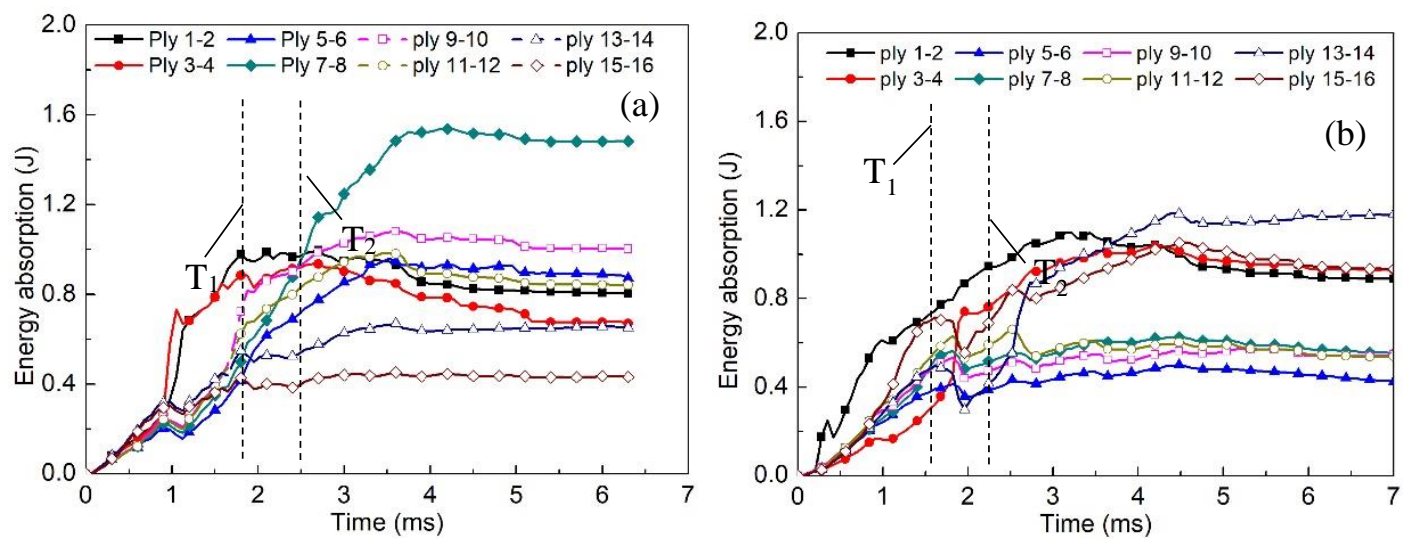

Fig. 19. Energy absorption histories for each ply during the impact process: (a) $\mathrm{CBC}$ laminate and (b) BCB laminate. 


\section{Conclusions}

This paper experimentally and numerically studied effects of fibre hybridization and fabric structures with carbon, glass and basalt fibre on low velocity impact resistance and damage mechanisms of composite laminates. The following conclusions could be drawn:

(1) Carbon layers showed relatively poor impact resistance compared to basalt/glass layers, due to brittle nature of carbon fibres. Glass and basalt fibre layers exhibited very similar behavior under low velocity impact.

(2) The stacking sequence of the three fibre types within composite laminates showed a significant effect on the impact resistance. In this study, compared to the pure CFRP laminate or hybrid laminate with carbon layers situated as the top and bottom face sheets, carbon layers as the core provided superior impact resistance.

(3) Full hybridization of three fibre types allowed greater global deformation of composite laminates in terms of damage area. The placement of carbon layers as the core achieved the highest energy absorption performance as compared to the same stacking configuration by hybridization with carbon and glass or basalt fibres.

(4) Weave fabric laminates exhibited smaller deformation areas and superior damage resistance than unidirectional fabric reinforced specimens. This was due to the fibre tow interlock in the in-plane direction.

(5) The force-displacement curve and damage mode from numerical simulation showed good correlation with experimental results and thus the effectiveness of the present FEA model was verified.

\section{Acknowledgements}

This work is supported by the National Natural Science Foundation of China (51575172) and the Hunan Provincial Innovation Foundation for Postgraduate (CX2018B198). Dr Guangyong Sun is a recipient of Australian Research Council Discovery Early Career Researcher Award (DECRA) at the University of Sydney.

\section{References}


[1] Petrucci R, Santulli C, Puglia D, Nisini E, Sarasini F, Tirillò J, et al. Impact and post-impact damage characterisation of hybrid composite laminates based on basalt fibres in combination with flax, hemp and glass fibres manufactured by vacuum infusion. Compos Part B Eng. 2015;69:50715.

[2] Sevkat E, Liaw B, Delale F, Raju BB. Effect of repeated impacts on the response of plainwoven hybrid composites. Compos Part B Eng. 2010;41:403-13.

[3] Hosur MV, Abdullah M, Jeelani S. Manufacturing and low-velocity impact characterization of foam filled 3-D integrated core sandwich composites with hybrid face sheets. Compos Struct. 2005;69:167-81.

[4] Cantwell W, Morton J. The impact resistance of composite materials-a review. composites. 1991;22:347-62.

[5] Yang B, Wang Z, Zhou L, Zhang J, Liang W. Experimental and numerical investigation of interply hybrid composites based on woven fabrics and PCBT resin subjected to low-velocity impact. Compos Struct. 2015;132:464-76.

[6] Sarasini F, Tirillò J, Valente M, Valente T, Cioffi S, Iannace S, et al. Effect of basalt fiber hybridization on the impact behavior under low impact velocity of glass/basalt woven fabric/epoxy resin composites. Composites Part A: Applied Science and Manufacturing. 2013;47:109-23.

[7] Sarasini F, Tirillò J, Valente M, Ferrante L, Cioffi S, Iannace S, et al. Hybrid composites based on aramid and basalt woven fabrics: Impact damage modes and residual flexural properties. Mater Des. 2013;49:290-302.

[8] Rivallant S, Bouvet C, Hongkarnjanakul N. Failure analysis of CFRP laminates subjected to compression after impact: FE simulation using discrete interface elements. Composites Part A: Applied Science and Manufacturing. 2013;55:83-93.

[9] Ebina M, Yoshimura A, Sakaue K, Waas AM. High fidelity simulation of low velocity impact behavior of CFRP laminate. Composites Part A: Applied Science and Manufacturing. 2018;113:166-79.

[10] Agrawal S, Singh KK, Sarkar PK. Impact damage on fibre-reinforced polymer matrix composite - A review. J Compos Mater. 2013;48:317-32.

[11] Sutherland LS, Guedes Soares C. The use of quasi-static testing to obtain the low-velocity impact damage resistance of marine GRP laminates. Compos Part B Eng. 2012;43:1459-67. [12] Gómez-del Río T, Zaera R, Barbero E, Navarro C. Damage in CFRPs due to low velocity impact at low temperature. Compos Part B Eng. 2005;36:41-50.

[13] Atas C, Icten BM, Küçük M. Thickness effect on repeated impact response of woven fabric composite plates. Compos Part B Eng. 2013;49:80-5.

[14] Atas C, Dogan A. An experimental investigation on the repeated impact response of glass/epoxy composites subjected to thermal ageing. Compos Part B Eng. 2015;75:127-34. [15] Amaro AM, Reis PNB, Neto MA. Experimental study of temperature effects on composite laminates subjected to multi-impacts. Compos Part B Eng. 2016;98:23-9.

[16] Xu Z, Yang F, Guan ZW, Cantwell WJ. An experimental and numerical study on scaling effects in the low velocity impact response of CFRP laminates. Compos Struct. 2016;154:69-78.

[17] Wang S-X, Wu L-Z, Ma L. Low-velocity impact and residual tensile strength analysis to carbon fiber composite laminates. Mater Des. 2010;31:118-25. 
[18] Santiuste C, Sanchez-Saez S, Barbero E. Residual flexural strength after low-velocity impact in glass/polyester composite beams. Compos Struct. 2010;92:25-30.

[19] Rivallant S, Bouvet C, Abi Abdallah E, Broll B, Barrau J-J. Experimental analysis of CFRP laminates subjected to compression after impact: The role of impact-induced cracks in failure. Compos Struct. 2014;111:147-57.

[20] Shi Y, Swait T, Soutis C. Modelling damage evolution in composite laminates subjected to low velocity impact. Compos Struct. 2012;94:2902-13.

[21] Pernas-Sánchez J, Artero-Guerrero JA, Zahr Viñuela J, Varas D, López-Puente J. Numerical analysis of high velocity impacts on unidirectional laminates. Compos Struct. 2014;107:629-34.

[22] Hashin Z. Failure criteria for unidirectional fiber composites. Journal of applied mechanics. 1980;47:329-34.

[23] Chang F-K, Chang K-Y. A progressive damage model for laminated composites containing stress concentrations. J Compos Mater. 1987;21:834-55.

[24] Hou J, Petrinic N, Ruiz C. A delamination criterion for laminated composites under lowvelocity impact. Compos Sci Technol. 2001;61:2069-74.

[25] Israr HA, Rivallant S, Bouvet C, Barrau JJ. Finite element simulation of $0^{\circ} / 90^{\circ} \mathrm{CFRP}$ laminated plates subjected to crushing using a free-face-crushing concept. Composites Part A: Applied Science and Manufacturing. 2014;62:16-25.

[26] Li X, Ma D, Liu H, Tan W, Gong X, Zhang C, et al. Assessment of failure criteria and damage evolution methods for composite laminates under low-velocity impact. Compos Struct. 2019;207:727-39.

[27] Sokolinsky VS, Indermuehle KC, Hurtado JA. Numerical simulation of the crushing process of a corrugated composite plate. Composites Part A: Applied Science and Manufacturing. 2011;42:1119-26.

[28] Cousigné O, Moncayo D, Coutellier D, Camanho P, Naceur H. Numerical modeling of nonlinearity, plasticity and damage in CFRP-woven composites for crash simulations. Compos Struct. 2014;115:75-88.

[29] Bull DJ, Scott AE, Spearing SM, Sinclair I. The influence of toughening-particles in CFRPs on low velocity impact damage resistance performance. Composites Part A: Applied Science and Manufacturing. 2014;58:47-55.

[30] Kostopoulos V, Baltopoulos A, Karapappas P, Vavouliotis A, Paipetis A. Impact and afterimpact properties of carbon fibre reinforced composites enhanced with multi-wall carbon nanotubes. Compos Sci Technol. 2010;70:553-63.

[31] Swolfs Y, Gorbatikh L, Verpoest I. Fibre hybridisation in polymer composites: A review. Composites Part A: Applied Science and Manufacturing. 2014;67:181-200.

[32] Tirillò J, Ferrante L, Sarasini F, Lampani L, Barbero E, Sánchez-Sáez S, et al. High velocity impact behaviour of hybrid basalt-carbon/epoxy composites. Compos Struct. 2017;168:305-12.

[33] Hung P-y, Lau K-t, Cheng L-k, Leng J, Hui D. Impact response of hybrid carbon/glass fibre reinforced polymer composites designed for engineering applications. Compos Part B Eng. 2018;133:86-90.

[34] Zhang D, Sun Y, Chen L, Pan N. A comparative study on low-velocity impact response of fabric composite laminates. Mater Des. 2013;50:750-6.

[35] Evci C, Gülgeç M. An experimental investigation on the impact response of composite materials. Int J Impact Eng. 2012;43:40-51. 
[36] Hosur MV, Adbullah M, Jeelani S. Studies on the low-velocity impact response of woven hybrid composites. Compos Struct. 2005;67:253-62.

[37] González EV, Maimí P, Sainz de Aja JR, Cruz P, Camanho PP. Effects of interply hybridization on the damage resistance and tolerance of composite laminates. Compos Struct. 2014;108:319-31.

[38] Lopresto V, Leone C, De Iorio I. Mechanical characterisation of basalt fibre reinforced plastic. Compos Part B Eng. 2011;42:717-23.

[39] Fiore V, Scalici T, Di Bella G, Valenza A. A review on basalt fibre and its composites. Compos Part B Eng. 2015;74:74-94.

[40] Najafi M, Khalili SMR, Eslami-Farsani R. Hybridization effect of basalt and carbon fibers on impact and flexural properties of phenolic composites. Iranian Polymer Journal. 2014;23:767-73.

[41] Ary Subagia IDG, Kim Y, Tijing LD, Kim CS, Shon HK. Effect of stacking sequence on the flexural properties of hybrid composites reinforced with carbon and basalt fibers. Compos Part B Eng. 2014;58:251-8.

[42] Sarasini F, Tirillò J, Ferrante L, Valente M, Valente T, Lampani L, et al. Drop-weight impact behaviour of woven hybrid basalt-carbon/epoxy composites. Compos Part B Eng. 2014;59:20420.

[43] Sun G, Tong S, Chen D, Gong Z, Li Q. Mechanical properties of hybrid composites reinforced by carbon and basalt fibers. International Journal of Mechanical Sciences. 2018;148:636-51.

[44] Chen D, Sun G, Meng M, Li G, Li Q. Residual crashworthiness of CFRP structures with preimpact damage - An experimental and numerical study. International Journal of Mechanical Sciences. 2018;149:122-35.

[45] Manikandan P, Chai GB. A layer-wise behavioral study of metal based interply hybrid composites under low velocity impact load. Compos Struct. 2014;117:17-31.

[46] Hongkarnjanakul N, Bouvet C, Rivallant S. Validation of low velocity impact modelling on different stacking sequences of CFRP laminates and influence of fibre failure. Compos Struct. 2013;106:549-59.

[47] Xin SH, Wen HM. A progressive damage model for fiber reinforced plastic composites subjected to impact loading. Int J Impact Eng. 2015;75:40-52.

[48] Yang L, Yan Y, Kuang N. Experimental and numerical investigation of aramid fibre reinforced laminates subjected to low velocity impact. Polymer Testing. 2013;32:1163-73.

[49] Version A. 6.13, Analysis User's Manual. Dassault Systemes Simulia Corp, Providence, RI. 2013.

[50] Ying S, Mengyun T, Zhijun R, Baohui S, Li C. An experimental investigation on the lowvelocity impact response of carbon-aramid/epoxy hybrid composite laminates. Journal of Reinforced Plastics and Composites. 2016;36:422-34.

[51] Zhao Z, Dang H, Zhang C, Yun GJ, Li Y. A multi-scale modeling framework for impact damage simulation of triaxially braided composites. Composites Part A: Applied Science and Manufacturing. 2018;110:113-25. 